\title{
Public opinion on weekend and evening outpatient clinics
}

\section{A J Churchill, C Gibbon, S Anand, M McKibbin}

\section{Change in working practice to allow better use of resources}

$\mathrm{T}$ he majority of consultants and specialist registrars in England and Wales voted against the new consultant deal. One point of conflict was the extension of the "normal working week" to $10 \mathrm{pm}$ on weekdays and $1 \mathrm{pm}$ at weekends. This change in working practice was proposed to allow better use of resources, such as outpatient clinics and operating theatres, which lie idle during the evenings and weekends and to offer patients greater choice of appointment times. We surveyed patients attending the ophthalmic departments at two large teaching hospitals to determine public opinion on the introduction of evening and weekend sessions.

During a 2 week period in September 2002, a questionnaire was given to outpatients attending the ophthalmic clinics at Bristol Eye Hospital and St James's University Hospital, Leeds. Patients were asked to state whether their current appointment times were suitable and which of the following time periods they would find convenient to attend the hospital: weekday morning, afternoon, early evening or late evening, and Saturday or Sunday mornings. An inbuilt control question tested reliability of responses and all those deemed unreliable were excluded from the final analysis. Employment status and other demographic details were recorded.

The number of questionnaires issued was 578 in Bristol and 450 in Leeds, with a response rate of $72 \%$ from Bristol and $71 \%$ from Leeds. After excluding incomplete or unreliable forms, 555 were included in the final analysis. The median age of those attending was higher in Bristol (70 years: range 1-94) compared to Leeds ( 64 years: range 1-93) reflecting a greater proportion of retired patients in Bristol (73\%) compared to Leeds (63\%). A slight preponderance of women attended both hospitals and reflected the demographic data collected on the outpatient computer for the preceding month.

There was no significant difference in the responses obtained from Leeds and Bristol so the results were combined. Eighty nine per cent of patients overall found their current appointment time convenient. Seven per cent preferred a different time within the existing framework. Only $4 \%$ stated that an appointment between 8 am and 5 pm Monday to Friday was inconvenient. When asked specifically about different time periods, both retired and employed patients ranked weekday mornings as the most convenient time $(79 \%$ and $75 \%$ respectively). Weekday evening clinics, 5 pm to $8 \mathrm{pm}$, were convenient to $45 \%$ patients but only $35 \%$ would be prepared to attend between $8 \mathrm{pm}$ and $10 \mathrm{pm}$. Saturday mornings were not convenient to $48 \%$ patients and Sunday mornings were unpopular for $66 \%$ patients (Table 1).

The study population was subcategorised into retired, employed, and patients with children. Sixty eight per cent of patients surveyed were retired. Of these, $37 \%$ would attend an appointment between $5 \mathrm{pm}$ and $8 \mathrm{pm}$ on a weekday, but only $29 \%$ would be prepared to attend from $8 \mathrm{pm}$ to $10 \mathrm{pm}$. Lack of confidence about travelling in the dark and poor public transport were the main deterrents recorded in this study. The concept of late clinics was also unpopular with individuals bringing children to the hospital (data not shown). These two groups of patients would prefer to attend a Saturday morning clinic rather than a Sunday morning or any time after $5 \mathrm{pm}$. Individuals engaged in employment preferred the option of an early evening clinic (up to $8 \mathrm{pm}$ ) rather than attending any time at the weekend.

In a smaller parallel study we surveyed patients attending day surgery for their opinions about evening and weekend operating sessions. Seventy one out of 103 questionnaires were deemed reliable. Ninety nine per cent of patients overall found their given operating time convenient. Weekday morning surgery was most popular $(89 \%)$ followed by weekday afternoons. When offered the choice of weekday evening or weekend morning surgery, patients ranked Saturday morning as most convenient (69\%) and late evening surgery (8-10 pm Monday to Friday) as least convenient. This response probably reflects the fact that the surgical group were mainly day case cataract patients and comparatively older than the overall group of patients attending the clinics.

We are not aware of any other reports seeking public opinion for the government's proposal to introduce evening and weekend outpatient and operating sessions. Our study demonstrates that the vast majority (89\% outpatients and 99\% surgical patients) are happy with their current appointment times whether they are employed or retired. The most popular time to attend the outpatient clinic or surgical unit is Monday to Friday 8 am-12 pm, regardless of age. Individuals bringing children to the clinic gave Saturday morning as their second choice while all other age groups found weekday $1 \mathrm{pm}-5 \mathrm{pm}$ the next most convenient appointment time. The concept of twilight operating sessions is unpopular with the elderly. If early evening sessions were introduced we would advocate against these being targeted at children or the elderly. Giving unpopular appointments is likely to result in high non-attendance thereby negating any attempts to use existing resources more efficiently.

The government has recently entered into discussions with the BMA about the

\begin{tabular}{|c|c|c|c|c|}
\hline Times & $\begin{array}{l}\text { Combined results } \\
\text { outpatients }\end{array}$ & $\begin{array}{l}\text { Retired age } \\
\text { group outpatients }\end{array}$ & $\begin{array}{l}\text { Working age } \\
\text { group outpatients }\end{array}$ & $\begin{array}{l}\text { Combined results } \\
\text { surgical patients }\end{array}$ \\
\hline 0800-1200 Mon-Fri & $77 \%$ & $79 \%$ & $75 \%$ & $89 \%$ \\
\hline 1300-1700 Mon-Fri & $74 \%$ & $78 \%$ & $68 \%$ & $79 \%$ \\
\hline $1700-2000$ Mon-Fri & $45 \%$ & $37 \%$ & $65 \%$ & $44 \%$ \\
\hline 2000-2200 Mon-Fri & $35 \%$ & $29 \%$ & $50 \%$ & $37 \%$ \\
\hline $0900-1300$ Sat & $52 \%$ & $50 \%$ & $55 \%$ & $69 \%$ \\
\hline 0900-1300 Sun & $44 \%$ & $50 \%$ & $48 \%$ & $62 \%$ \\
\hline
\end{tabular}


new deal and we shall have to wait to see what new proposals are tabled. We would suggest that they might wish to consider the opinions of the users of the NHS as well as the medical profession when renegotiating the consultant contract. If the government plans to increase NHS flexibility and allow patients to choose their appointment times only $4 \%$ of clinic patients and $1 \%$ of surgical patients will opt for an evening or weekend appointment. While the authors are sympathetic to the more efficient use of existing NHS resources, we would suggest that the increased costs of staffing sessions outside of the existing framework cannot be justified for such small numbers.

\section{Authors' affiliations}

A J Churchill, Division of Ophthalmology, Bristol Eye Hospital, Lower Maudlin Street, Bristol BSI 2LX, UK

C Gibbon, Bristol Eye Hospital, Bristol, UK $S$ Anand, M McKibbin, St James's University Hospital, Leeds, UK

Correspondence to: Amanda J Churchill; a.j.churchill@bris.ac.uk

\section{New BJO online submission and review system}

The Editors of British Journal of Opthalmology are pleased to inform authors and reviewers of its new online submission and review system. Bench>Press is a fully integrated electronic system which uses the internet to allow rapid and efficient submission of manuscripts, as well as the entire peer review process to be conducted online.

Authors can submit their manuscript in any standard word processing software. Graphic formats acceptable are: .jpg, .tiff, .gif, and eps. (Nb. Multipage PowerPoint presentations are NOT acceptable.) Text and graphic files are automatically converted to PDF for ease of distribution and reviewing purposes. Authors are asked to approve their submission before it formally enters the reviewing process.

To access the system click on "SUBMIT YOUR MANUSCRIPT HERE" on the BJO homepage: http://www.bjopthalmol.com/, or you can access Bench>Press directly at http://submit-bjo.bmijournals.com/.

We are very excited with this new development, it really is simple to use and should be a big improvement on the current peer review process. Full instructions can be found on Bench>Press and BJO online. Please contact Natalie Davies, Project Manager, ndavies@bmigroup.com for further information.

\section{Pre-register}

We would be grateful if all British Journal of Opthalmology authors and reviewers pre-registered with the system. This will give you the opportunity to update your contact and expertise data, allowing us to provide you with a more efficient service.

\section{Instructions For Registering}

1. Enter http://submit-bjo.bmijournals.com

2. Click on "Create a New Account" in the upper left hand side of the Bench>Press

homepage.

3. Enter your email address in the space provided.

4. Choose a password for yourself and enter it in the spaces provided.

5. Complete the question of your choice to be used in the event you cannot remember your password at a later time.

6. Click on the "Save" button at the bottom of the screen.

7. Check the email account you registered under. An email will be sent to you with a verification number and URL.

8. Once you receive this verification number, click on the URL hyperlink and enter the verification number in the relevant field. This is for security reasons and to check that your account is not being used fraudulently.

9. Enter/amend your contact information, and update your expertise data.

10. Please note: You only need to create a new account once. If you submit to another BM Publishing Group journal you can use the same email address and password 